\title{
The Role of Playing Video Games on School Achievement
}

Preliminary communication _ DOI 10.22522/cmr20180234 _ received on 10 October 2017 UDK: $795: 371.26$ _ 316.72:316.774

\section{Andrej Malek}

Department of Croatian Studies, University of Zagreb, Zagreb, Croatia.

Email: malek.andrej@yahoo.com

\section{Marjan Ninčević, PhD}

Department of Croatian Studies, University of Zagreb, Zagreb, Croatia.

Email:mnincevic@hrstud.hr

\section{Dunja Jurić Vukelić}

Department of Croatian Studies, University of Zagreb, Zagreb, Croatia.

Email: djuric@hrstud.hr (corresponding author)

\section{Abstract}

The subject of the present research was the possible effect that playing video games can have on students. The focus is on the role that playing video games can have on school grades and school achievement in general. Problems in the research of effects of video games were outlined in the paper. The paper also presents the results of previous research of the impact of video games and often other media on school achievement. Elementary schools and high schools students participated in the present research. The results are generally as expected considering previous studies, and certain positive effects were observed, such as the fact that students who play video games achieve better overall success when compared to students who do not play games at all.

Keywords: video games, school achievement, school success 


\section{Introduction}

Many people working in the field of education, especially teachers of, as they say, the old system, have a negative attitude towards video games. As the research has been conducted in schools, one of the principal's reaction especially pointed out: during the discussion on permission to conduct student polling, the principal asked about the theme of the paper, and her reaction to the title role of video games in the student's overall success was: "Oh, yes, that's a very big problem." We notice negative impression in older population, and it is common to hear statements such as: these young people do nothing, just sit around the computer all day long or young people no longer socialize, they just hang out in front of screens. Even if we agree with some of the statements above, it seems wrong to blame video games alone for poorer student success. But since video games are so popular that sometimes they are considered a kind of art, they indubitably affect the lives of consumers, either positively or negatively.

But how do video games affect students? It is indubitable that most children and adolescents at least sometimes play video games. For this reason, since the 1980s studies have been carried out on the subject of video games, mostly focused on negative impacts, especially the impact of violent video games, but certain positive impacts were also found. Some of the negative and positive impacts, found by previous research, are presented in this paper. These studies leave space for various interpretations, and therefore the main issues of these studies are also briefly presented in the paper. In order to understand the role of video games, as well as the results of the earliest research on the role of video games, we will briefly present the history of video games.

\section{A Short History of Video Games}

The history of video games goes back to 1948, when the first electronic device for entertainment was designed (Kent, 2010). Over the next decade the development of video games accompanies computer development. The first commercial success of video games goes back to 1972, when the arcade game Pong, a table tennis simulation, emerged, followed by the development of arcade games such as pinball. Like other arcade games, Pong was located in public places, cafes, restaurants, and playrooms, and its popularity has stimulated tendency for video games in homes. Magnavox Odyssey, the first home game console, was released that year, which 
offered up to 28 different video games. Almost all the games on that console were sports or action genre. In 1977, as a result of the development of the microprocessor, the Atari VCS (Atari 2600) game console appeared. The importance of such consoles was priceless. For the first time, video games, the goal of which was not simply to add balls or destroy opponents, but already require some strategic thinking, appeared. During the next year, the impact of video games on players has become a new research problem, especially with children and adolescents, who showed the most interest for the games. At the same time, the development of PCs had begun. The number of computer users and consoles grew every year, and in the meantime, the number of home video game players exceeded the number of arcade video gamers in the public, which also influenced the greater isolation of people since the arcade video games were usually played in company.

In 1984, Apple Macintosh, the first home computer with mouse and graphical interface appeared. This innovation further brought computers closer to the users, and consequently made video games even more accessible. The same innovation has had an impact on the scientific community since the first studies of video games and school success have been reported since 1985 . These surveys raise questions about how long players were playing video games, and the average response amounts to 14 months, or approximately since Apple Macintosh could be purchased (Burgess, 2012).

In the last decade of the 20th century, the greatest step in the quality of graphics and the complexity of the games was made. Following the gradual development of games from the previous decade, games that introduce a third dimension into the world of video games, making a stronger impression of reality and allowing stronger emotional connectivity with characters from video games. The popularization of 3D games has resulted in the emergence of action-packed First Person Shooter (FPS) video games, featuring explicit shootings and violence, which resulted in the Entertainment Software Rating Board, better known as ESRB, which prescribes the suitable age for certain game (Parks, 2012), or PEGI, Pan European Game Information, in Europe. Hardware of game consoles and computers is continually improving, enabling better graphics and more complex video games. In recent years we have witnessed the re-emergence of so-called virtual reality and popular VR glasses that give players the impression that they really are in the world of video games. 


\section{Problems of Video Games Impacts on Behaviour}

A leading problem is how to explore the direct impact of video games on children and adults. No behavior can be attributed exclusively to video games because it is generally influenced by a number of factors. According to Nakaya (2015), under the influence of their own expectations, researchers often make different conclusions. For example, one can argue that video games are associated with violence in schools, while others may argue that they are not closely related, with the same evidence that brought them to those opposite conclusions. A specific example of the problem described is the interpretation of research where participants after playing violent video games showed a greater tendency to aggressive behavior, such as releasing loud noises to other people. Anderson and Bushman (2001) believe that such behaviour is a result of violent video games, while Ferguson et al. (2008) give a different interpretation and believe that this research speaks little about actual tendency to violence, since respondents would not show that kind of signs of aggression outside the lab. A similar ambiguity of the results can be seen in the laboratory research in 2013 with high school students as participants. They were divided into two groups. One group played non-violent games such as pinball and minigolf, and the second group played violent games Grand Theft Auto III and Grand Theft Auto San Andreas. Both groups were given sweets they were free to consume, however, the students were given a clear note that the candy was harmful to their health. The results of the research showed that the group playing violent games had eaten more sweets than the other group, which led scientists to conclude that violent games have a negative influence on student self-control (Nakaya, 2015). But there are at least two alternative interpretations of these findings. The fact that one type of game has affected eating more sweets does not have to say anything about self-control. The first group playing a non-violent video game was playing a pinball, a game where constant alertness and concentration on the ball is required, as well as readiness to react if needed, or a minigolf that also requires high concentration, patience and calmness. On the other hand, a group playing violent video games played Grand Theft Auto series games. These games are dynamic, but require less concentration and more agility and speed, so they provide more excitement. The result is comparable to film-based research, where Tal, Zuckerman and Wansink (2014) came to the conclusion that the most food is eaten when watching action movies. The second interpretation of this research may 
be reduced to the time available during game play which can be used for picking up candy. Pinball and minigolf players will probably spend more time concentrating on the events than the Grand Theft Auto players, as it is almost always possible to take a break in the latter game.

In 2011, Pediatrics published a study about video addiction issues. Participants were third, seventh and eighth grade students who were interviewed three times during a three-year period. This study is an example of a well-designed and conducted research, since the same students were interviewed during a given period, allowing authors to observe certain regularity in the responses as well as tracking changes in that period. According to the results, children who reported video games addiction were also more prone to anxiety and depression and they had poorer school success (Nakaya, 2015). Perhaps the most obvious problem about described study would be the readiness of the student to take the survey and their previous knowledge, so they might have responded similar to earlier responses while reading questions hastily.

Research results are often the subject of different interpretations. However, it is certain that video games have a major impact on people's behavior since the so-called gaming industry is nowadays more developed than ever before, and that development continues. For example, in 2012 in the United States, $69 \%$ of the population played video games, either on a computer or on various consoles. The growing popularity of video games is seen in the income achieved: in 2006, only in the United States expenditure on video games, excluding the consoles and other hardware, was $\$ 7.4$ billion, almost three times more than in 1996 when $\$ 2.5$ billion was spent (Parks, 2012). The stunning fact is that in the next ten years in the United States consumption was tripled, and in $2016 \$ 24.5$ billion was spent on video games (Theesa.com, 2016). With inflation calculated, it is again 20.5 billion more than 20 years ago. The gaming industry is certainly most developed in the United States, where it accounts for about 30\% of the world's video game consumption.

Taking into account China's share of consumption, which also amounts to around $30 \%$, it is apparent that in the rest of the world video game consumption is more moderate. This is important since spending money also tells how much video games are important to the locals of certain areas, and it gives a new look at the research on that topic. The United States, Japan, South Korea, Germany, and the United Kingdom are not only countries with the highest consumption on video games per capita, but also most concerned with the impact of video games on society and children (The games industry in numbers, 2017). 
In the countries listed above gamers are mainly grown-ups: in the United States, the average gamers age is 31, while in the United Kingdom 69\% of the population between 21 and 35 years of age plays video games. This certainly affects consumption statistics, so when it comes to children and adolescents, time spent playing video games should also be taken into account. Time children spend playing video games is difficult to measure, data is limited to surveying children or their parents. Even that kind of research can be imprecise, as children show tendency to reduce the number of hours reported as spent playing video games, while parents could artificially increase it. There are clear reasons for that: parents often think that children spend too much time in front of the screen and they are prone to exaggerate their assessment of time their kids spend playing video games. Children, however, know how to reduce the number of hours to avoid the inconvenience, so that the examiner does not get the impression that the child is playing video games all day. Another reason may be unintentional and it concerns the impression that time is flying while we are having fun. Children often have the impression that they spent much less time playing video games than they really did.

\subsection{The Impact of Video Games in General}

\subsubsection{Negative Impact of Video Games}

As has been said before, implicitly negative attitudes prevail over the impact of games on children. According to the Statista portal, the number of hours children from 3 to 15 years of age spend playing video games in the United Kingdom (UK) from 2013 to 2016 is growing. According to Statista, children between the ages of 12 and 15 spend the most time playing video games.

Improved visual quality of games, although important, is probably not the only reason for increased time children and young people spend playing video games, but the growing popularity of online video games. According to Kowert (2015), in 2013, 700 million people have played online video games and many players admit they play between 10 and 20 hours a week. Therefore, it is justified to talk about addiction to video games and their impact on addicts. How to recognize addiction? The National Institute of Media and Family (NIMF) from the United States states the following patterns of behavior and opinions as the first sign of addiction to video games:

1. Playing video games creates an intense feeling of satisfaction or guilt.

2. Video game players are thinking about video games even when they do not play. 
3. The time a player plays video games increases, which negatively affects family, school success, career and/or social life.

4. Lying related to video games where players deny their addiction and about the time they spend playing video games.

5. When not playing video games, the player feels anger or depression.

6. The player prefers playing video games (especially online) than socializing with friends or partners.

7. Physical pain is present due to improper sitting, bad sleep, eye irritation.

8. The player neglects personal hygiene or skips meals (Marcovitz, 2011).

Surely the most notorious negative impact of video games, the subject of most research, is violence. A connection between exposure to violent content and the tendency to aggressive behavior, both for children and adults, has been found in numerous studies (Anderson et al., 2003; Anderson, Bushman, 2001). Exposure to such content makes aggressive thoughts emerge and strengthen. That applies also to other media, but the effect of video games is the most obvious because a gaming session can take a long time and video games often place a person in a certain role with which they can associate emotionally (Bogost, 2007).

\subsubsection{Positive Impacts of Video Games}

Positive effects of video games are less talked about. They could be divided into two groups: ability improvement and effects on learning. Playing games that require certain skills can lead to improvement of these skills. For example, playing games where you need to quickly count certain objects can improve visual perception (Green, Bavelier, 2006). Learning effects are mostly related to games with learning as primary purpose, such as various simulations, and using video games in teaching often reinforces the interest of students (Gentile, Gentile, 2008). But learning can also be a by-product of playing games in which learning is not the primary purpose. People often learn certain things by playing video games designed exclusively for fun. For example, it is possible to improve the foreign language in which the video game is played, or learn certain geographic and historical facts by playing strategy games (Squire, 2003; Devlin, 2011). 


\subsubsection{The Role of Video Games in School Success - Results of Previous Research}

Numerous studies examined the effects of video games on behavior, and a smaller number of researches were focused on the effects on education. The beginnings of the research date back to 1980s, as well as the first attempts to implement video games in education (Jones, Kennedy, Bittner, 1981; Chaffin, Maxwell, Thompson, 1982). One of the earliest researches was carried out by Gary L. Creasey and Barbara J. Myers (1986). Participants were students aged 9 to 16 years. The authors published an ad in a local newspaper searching for parents who planned to buy children to play a game console or computer for upcoming holidays, parents whose children own a game console or computer for at least a year, and parents who are not in favor of getting their kids a game console or computer. Thus, the parents of children who responded to the ad were split into three groups. They were given two equal questionnaires at a certain time interval, explaining their daily habits, extracurricular activities, and relationships with school colleagues. Part of the daily habits included questions that make it known the time a pupil spent watching television, listening to radio and playing video games. Changes in school success were not found, but there was a decrease in the time spent in writing homework on students who got a console or computer during the research.

Similar research was conducted, almost simultaneously on a larger sample of students by Mary B. Harris and Randall Williams in 1985. That was the first study to find the correlation between the money spent on video games and the time spent playing them, the school grades and time spent learning. The authors started from the assumption that time spent playing video games is actually the time they would otherwise spend on learning, that is, students who spend more time playing video games spend less time learning. The results have also shown that there is no correlation between the two (Harris, Williams, 1985).

A study that provided a different perspective of video games and school success correlation was published in 1988. Lieberman, Chaffee and Roberts (1988) put the time spent on the computer in the second plan, but considered the student's motives and purpose of computer usage. Four groups were formed as a result of the research: recreational, intellectual, multiusers and low users. Recreational users played video games a great deal and achieved the lowest success in school. Intellectual users use the computer to fulfill school tasks. Their 
school success proved to be the best. Multi-users use the computer in two ways: to complete school tasks, but also to play video games. School success is somewhat worse than intellectual users. Low users rarely or never use the computer, but their school success was better than in recreational users.

Some studies disclaimed the correlation between playing video games and school success (Lin, Lepper, 1987; Borzekowski, Robinson, 2005) and also between playing video games and intelligence, aggressive behavior, prosocial behavior and social integration (Van Schie, Wiegma, 1997). In studies in which correlations have been found, poorer school success is usually determined by the time that students spend playing video games during work days (Sharif, Sargent, 2006) or the first symptoms of addiction, such as mood swings, reticence, or helplessness (Skoric, Ching Teo, Neo, 2009).

Since the world of video games is closely related to the development of computer technologies that, as is known, are rapidly evolving, the world of video games is prone to frequent and rapid changes. Progress of hardware is accompanied by software advancements, and in the world of video games, over the past ten years, franchises have emerged, giving each year or every few years a new title that often offers some innovativeness to the earlier title. It creates a hyper-production of video games and the ability to almost always get some new title. Consequently, it is important to consider the most recent studies in order to follow any changes in the behavioral habits and behavior patterns of a few years ago. Aaron Drummond and James D. Sauer published an article in 2014 in which they analyzed the International Student Assessment data from 22 countries in which more than 192,000 15-year-olds participated. The 22 countries that were considered were members of the Organization for Economic Cooperation and Development and, according to the International Monetary Fund, considered as developed countries. The aim of the study was to investigate the role of video games in school achievement in the field of science, mathematics and reading. In the countries considered, 192975 students regularly played offline video games and 192,741 students played online. Results have shown that the frequency of video game playing was not a factor that affects school success. But this is only true for total online and offline data. Players who played offline single player games achieved better results than students who did not play video games at all, but non-players had better results than students playing online video games (Drummond, Sauer, 2014). 


\section{Methodology of the Research}

The aim of the study was to examine whether there is a correlation between the frequency of video game play and school success. Also, as previous research pointed to the difference in preferences among gender, this research seeks to investigate whether such differences exist, and the differences between primary and secondary students. Additionally, the intention was to explore the possible correlation between the genres of video games that children play and the school success these children achieve.

The present study included 208 students from the rural area of Veliki Grđevac and Velika Pisanica and the urban area of Bjelovar and Virovitica. Out of 208 students, 115 were female and 93 male. The survey was conducted in May 2016. The date was chosen so the students could give as precise details as possible about their success at the end of the current school year. Only the students of the final grades of elementary and secondary schools participated. Survey was conducted after the approval of the school principals and parents of the students. Surveys were provided to the schools and the students filled them out during the teaching of psychology, mathematics or religion. Of the collected surveys, one was not valid, so 207 surveys were included in the final analysis, of which 95 are high school students and 112 are primary school students.

The students responded to a total of 25 questions divided into 4 groups. The first group contained general information about the student: gender, school, previous school success and expected success at the end of the current year. The second group of questions provided information on how much time the student spends playing video games and which games were played most often. Furthermore, students gave information on when they first started playing video games. The third group of questions contains questions of the Likert type, where students answered 12 questions, with several questions spotting indicators of video game addiction included. The fourth group was actually only one open-ended question where participants could write something that they consider important and not covered by the previous questions. 


\subsection{Results and Discussion}

\subsubsection{Factor Structure and Reliability of the Questionnaire}

For the purpose of testing the cogency of the factor matrix computation, we tested the Bartlett test for correlation matrix significance and Kaiser-Meyer-Olkin sampling probability test of the questionnaire used. The Kaiser-Meyer-Olkin test amounted to 0.82, which is a good value for factorization, and Bartlett's test showed the significance of a correlation matrix with a risk of less than $1 \%$. After the extraction of the factors, a clear difference between the characteristic roots of the second and third factors was shown. The difference is apparent in Figure 1, indicating the eligibility of a two-factor structure, as expected.

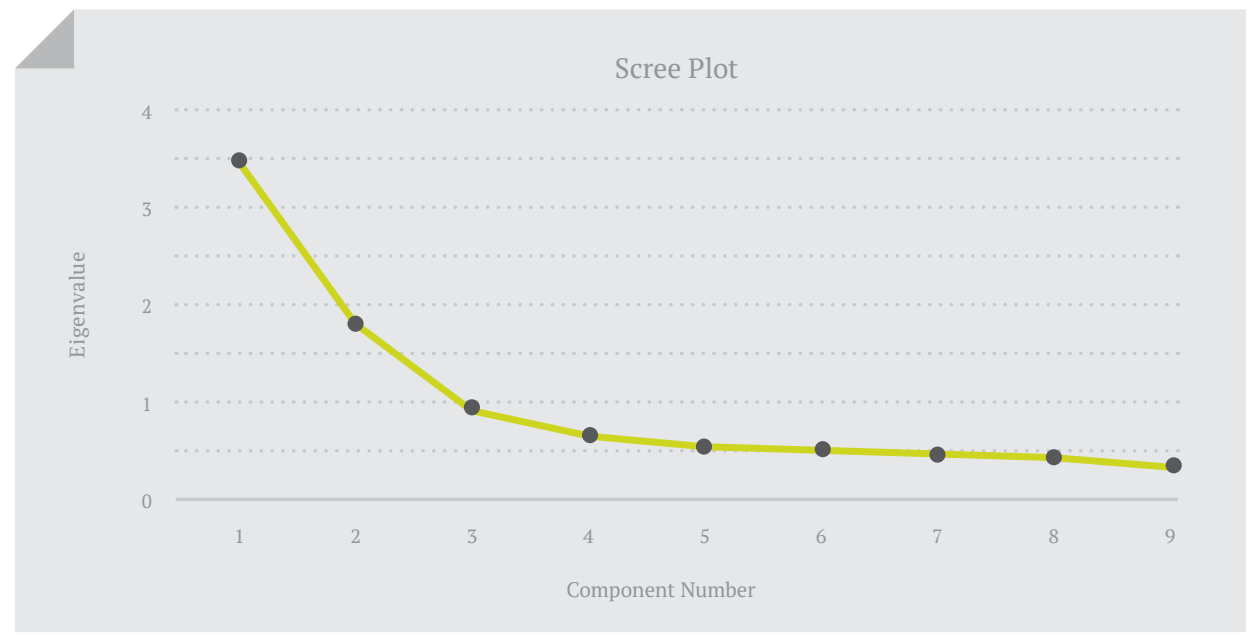

Figure 1. Scree test for the number of factors $(\mathrm{N}=207)$

Table 1 shows the results of the factor analysis of the questionnaire responses. Two factors were extracted using the method of common factors, which together account for $55.92 \%$ of the total variance. Cronbach alpha was 0.80 and the average correlation between the items was $r=0.53$. 
Table 1. Factor structure of the results on the questionnaire of the attitudes towards the video game

\begin{tabular}{|c|c|c|}
\hline & \multicolumn{2}{|c|}{ Component } \\
\hline & 1 & 2 \\
\hline I consider video games more fun than socializing with friends & ,758 &,- 359 \\
\hline I consider video games more fun than sports &, 727 &,- 444 \\
\hline I consider video games more fun than school &, 560 &,- 374 \\
\hline Video games are my favorite way of entertainment & ,749 &,- 038 \\
\hline I would like to spend more time playing video games & ,736 &,- 128 \\
\hline I think I play video games too much & ,482 &, 590 \\
\hline Video games take away the time I would otherwise spend learning & ,445 &, 510 \\
\hline Video games have a negative impact on my success at school & ,401 & ,662 \\
\hline I've experienced some inconvenience at school because of video games & ,263 &, 569 \\
\hline Extraction Method: Principal Component Analysis. & & \\
\hline a. 2 components extracted. & & \\
\hline
\end{tabular}

The factor analysis showed two latent variables that can be explained in line with expectations. The first factor includes the first five items in Table 1 and refers to the attitude towards video games. The last four items, as shown in Table 1, belong to the second factor, and they relate to the symptoms of video game addiction: thinking that too much time was spent playing video games, which take time that would otherwise be devoted to learning and that video games negatively affect school success.

\subsubsection{Descriptive Statistics}

Of the 207 participants, 166 or $80.2 \%$ of them play video games. Open World games (Grand Theft Auto in the first place), which often contain a lot of violence, were the most popular, played by almost half of the participants. Multiplayer games follow by popularity, almost entirely online games, among which the League of Legends prevails. 


\section{Frequency}

Several times a month

1-2 times a week

3-4 times a week

5-6 times a week

Every day

Total
37

32

21

27

49

161

\section{Percent (\%)}

22.3

19.3

12.7

16.3

29.5

100

Data about how often participants play video games were dominated by two extremes: 49 (29.5\%) of participants play every day, 37 (22.3\%) of participants play several times a month, 32 (19.3\%) participants play 1 to 2 times a week, 21 (12.7\%) of participants play 3 to 4 times a week and 27 (16.3\%) of participants play 4 to 6 times a week (Table 2). As for the time spent playing video games, $39.8 \%$ of participants spend less than an hour playing video games, and $28.9 \%$ play from 1 to 4 hours (Table 3 ). The response range was made sensitive to highlight the players who spend a lot of time playing video games, and that is a relatively large number: out of 166 students who play video games, 52 students play more than 4 hours, and 7 of them play more than 8 hours daily. As expected, boys played video games much more often than girls.

Table 3. Daily time spent playing

\section{Frequency}

Less than 1 hour

1-4 hours

4-6 hours

6-8 hours

More than 8 hours

Total

\section{6}

48

29

16

7

166
Percent (\%)

39.8

28.9

17.5

9.6

4.2

100

The mean school grade for students who play video games is 4.37 and the expected success at the end of the school year is 4.43 . There was no statistically significant difference between the students who played video games and those who did not play, either in the overall success of the school or in the expected success. The expected difference in overall success or the number 
of hours of play per day was not confirmed. A partial explanation of these findings certainly could be found in the survey results, according to which even $91.3 \%$ of the students assess their overall success at the end of the school year as very good or excellent, which certainly leads to variability restriction. Of the 207 surveyed students, only 18 assessed their overall success rate as good, as well as expected overall success at the end of the current school year.

Also, the samples were not even in size, considering that 166 pupils play video games and only 41 students did not play. However, interesting results were obtained by analyzing school success according to the frequency of playing video games. The results are shown in Table 4 .

Table 4. School success according to frequency of playing video games

\begin{tabular}{|c|c|c|c|c|c|}
\hline & $\begin{array}{l}\text { Several times } \\
\text { a month }\end{array}$ & 1-2 times a week & $\begin{array}{l}\text { 3-4 times } \\
\text { a week }\end{array}$ & $\begin{array}{l}5-6 \text { times } \\
\text { a week }\end{array}$ & Every day \\
\hline $\begin{array}{l}\text { School grades from } \\
\text { last school year }\end{array}$ & 4.43 & 4.42 & 4.14 & 4.44 & 4.33 \\
\hline Expected grade & 4.57 & 4.52 & 4.29 & 4.37 & 4.38 \\
\hline $\begin{array}{l}\text { School grades from } \\
\text { last school year - } \\
\text { primary school }\end{array}$ & 4.41 & 4.32 & 4.00 & 4.36 & 4.38 \\
\hline $\begin{array}{l}\text { Expected grade in } \\
\text { primary school }\end{array}$ & 4.47 & 4.44 & 4.09 & 4.29 & 4.23 \\
\hline $\begin{array}{l}\text { School grades from } \\
\text { last school year - } \\
\text { high school }\end{array}$ & 4.45 & 4.53 & 4.30 & 4.54 & 4.27 \\
\hline $\begin{array}{l}\text { Expected grade in } \\
\text { high school }\end{array}$ & 4.65 & 4.60 & 4.50 & 4.46 & 4.55 \\
\hline
\end{tabular}

Figure 2 confirms a correlation between overall success and frequency of video game play. According to the data, students who play video games several times a month and those who play 1 to 2 times a week have the best grades. These results are in line with expectations. Students who play video games 1 to 2 times a week are probably playing video games weekends, which, as shown by Sharif and Sargent (2006), does not have to have a negative reflection on grades. If they do not play on weekends, they play rarely enough so that it does not have a negative impact on their grades. 


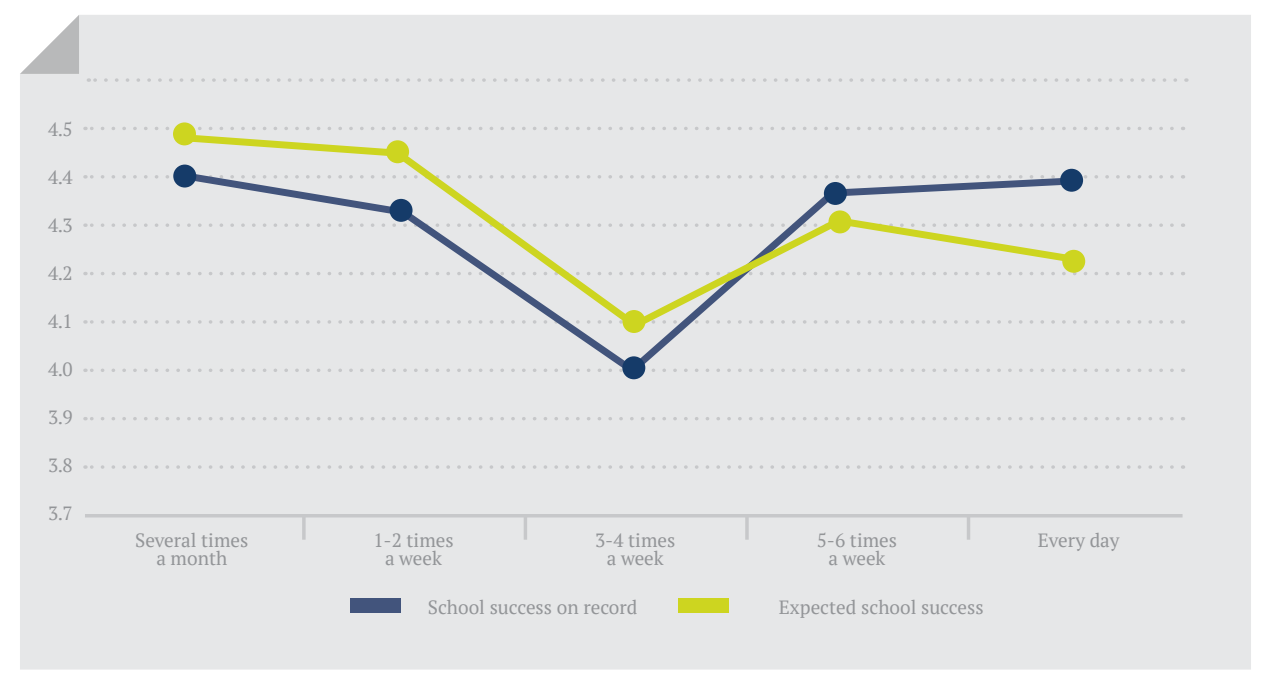

Figure 2. School success (on record and expected) due to the frequency of playing video games

Children playing 5-6 times a week or every day have slightly worse grades, but again better than children playing 3-4 times a week. This result was probably influenced by various factors. In a similar research, Van Schie and Wiegma (1997) pointed out intelligence as a possible mediating variable: not only the significant role of intelligence in school achievements, but also the possibility that playing video games stimulates the development of intelligence. It is also possible, as Lin and Lepper (1987) interpreted similar results, that the time the students spent playing video games was not the time they would use for video games, but for some other form of entertainment.

Finally, a regression analysis was conducted, assuming the frequency of playing video games as a predictor and the previous / expected school success as a criterion variable. The results shown in Table 5 show that the frequency of playing was a good predictor of school success, that the students who played video games more often had poorer school success than the students who were more moderate in playing video games. 


\begin{tabular}{|c|c|c|c|c|c|}
\hline \multirow{2}{*}{ Model } & \multicolumn{2}{|c|}{$\begin{array}{l}\text { Unstandardized } \\
\text { Coefficients }\end{array}$} & \multirow{2}{*}{$\begin{array}{c}\text { Standardized } \\
\text { Coefficients } \\
\text { Beta }\end{array}$} & \multirow{2}{*}{$\mathrm{t}$} & \multirow{2}{*}{ Sig. } \\
\hline & B & Std. Error & & & \\
\hline (Constant) & 4.58 & 0.11 & - & 41.51 & 0.00 \\
\hline $\begin{array}{l}\text { How often do you play } \\
\text { video games }\end{array}$ & -0.05 & 0.03 & -0.11 & -1.43 & 0.15 \\
\hline
\end{tabular}

\section{Conclusion}

The results of the present study suggest that the vast majority of participants, high school students, play video games, and nearly half of the participants most commonly played online multiplayer games. Nearly third of the participants play video games every day, 1 to 4 hours daily. As expected, boys played video games much more often than girls did. Although there was no statistically significant difference between the students who played video games and those who did not play in the overall achieved or expected school success, the frequency of playing was a good predictor of school success in a way that students who played video games more often had poorer school success than the students who were more moderate in playing video games.

\section{Reference List}

- Anderson, C. A., Bushman, B. J. (2001). Effects of Violent Video Games on Aggressive Behavior, Aggressive Cognition, Aggressive Affect, Physiological Arousal, and Prosocial Behavior: A Meta-Analytic Review of the Scientific Literature. Psychological Science, 12, 353-359.

- Anderson, C. A., Berkowitz, L., Donnerstein, E., Huesmann, L. R., Johnson, J., Linz, D., Malamuth, N., Wartella, E. (2003). The influence of media violence on youth. Psychological Science in the Public Interest, 4, 81-110.

- Bogost, I. (2007). Persuasive Games The Expressive Power of Videogames. Cambridge, Massachusetts, London: The MIT Press. - Borzekowski, D. L. G., Robinson T. N. (2005.) The Remote, the Mouse, and the No. 2 Pencil The Household Media Environment and Academic Achievement Among Third Grade Students. Archives of Pediatrics and Adolescent Medicine, 159, $607-613$.

- Chaffin, J. D., Maxwell, B., Thompson, B. (1982). ARC-ED curriculum: The application of video game formats to educational software. Exceptional Children, 49 (2), 173-178.

- Creasey, G. L., Myers, B. J. (1986). Video games and children: Effects on leisure activities, schoolwork, and peer involvement. Merrill-Palmer Quarterly, 251-262.

- Devlin, K. (2011). Mathematics education for a new era: Video games as a medium for learning. Natick, Massachusetts: A K Peters, CRC Press. 
- Drummond, A., Sauer, J. D. (2014). Video-games do not negatively impact adolescent academic performance in science, mathematics or reading. PloS one, 9 (4), e87943.

- Ferguson, C. J., Rueda, S. M., Cruz, A. M., Ferguson, D. E., Fritz, S., Smith, S. M. (2008). Violent video games and aggression: Causal relationship or byproduct of family violence and intrinsic violence motivation? Criminal Justice and Behavior, 35 (3), 311-332.

- Gentile, D. A., Gentile, J. R. (2008). Violent video games as exemplary teachers: A conceptual analysis. Journal of Youth and Adolescence, 37 (2), 127-141.

- Green, C. S., Bavelier, D. (2006). Effect of action video games on the spatial distribution of visuospatial attention. Journal of experimental psychology: Human perception and performance, 32 (6), 1465.

- Harris, M. B., Williams, R. (1985). Video games and school performance. Education, 105 (3), 306-309.

- Jones, M. B., Kennedy, R. S., Bittner, Jr. A. C. (1981). A video game for performance testing. The American Journal of Psychology, 94, 143-152.

- Kent, S. L. (2010). The Ultimate History of Video Games: from Pong to Pokemon and beyond... the story behind the craze that touched our lives and changed the world. New York: Three Rivers Press.

- Kowert, R. (2014). Video games and social competence. New York, London: Routledge.

- Lieberman, D. A., Chaffee, S. H., Roberts, D. F. (1988). Computers, mass media, and schooling: Functional equivalence in uses of new media. Social Science Computer Review, 6 (2), 224-241.

- Lin, S., Lepper, M. R. (1987). Correlates of Children's Usage of Videogames and Computers. Journal of Applied Social Psychology, 17 (1), 72-93.

- Marcovitz, H. (2011). Are Video Games Harmful? San Diego: Referencepoint Press.

- Nakaya, A. C. (2014). Video Games and Youth. San Diego: Referencepoint Press.

- Parks, P. (2012). Video Games. San Diego: Referencepoint Press.

- Sharif, I., Sargent, J. D. (2006). Association between television, movie, and video game exposure and school performance. Pediatrics, 118 (4), 1061-1070.

- Skoric, M. M., Teo, L. L. C., Neo, R. L. (2009). Children and video games: addiction, engagement, and scholastic achievement. Cyberpsychology \& behavior, 12 (5), 567-572.

- Squire, K. (2003). Video Games in Education. International journal of intelligent simulations and gaming, 2, 17-26.

- Statista.com (2017). Time spent gaming weekly among children UK 2016. Retrieved from https://www.statista.com/ statistics/274434/time-spent-gaming-weekly-among-children-in-the-uk-by-age/. 15 February 2017.

- Tal, A., Zuckerman S., Wansink, B. (2014). Watch What You Eat: Action-Related Television Content Increases Food Intake. Jama Internal Medicine, 174 (11), 1842-1843.

- The games industry in numbers. (2017). Retrieved from https://ukie.org.uk/research. 17 February 2017.

- Theesa.com (2016). U.S. Video Game Industry Generates \$30.4 Billion in Revenue for 2016. Retrieved from http://www. theesa.com/article/u-s-video-game-industry-generates-30-4-billion-revenue-2016/. 15 February 2017.

- Van Schie, E. G. M., Wiegma O. (1997). Children and Videogames: Leisure Activities, Aggression, Social Integration, and School Performance. Journal of Applied Social Psychology, 27, 1175-1194. 


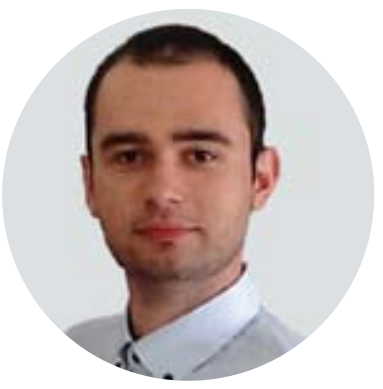

Andrej Malek

Andrej Malek has an MA in History, History Education and Philosophy Education. Currently he is in vocational training at Eugen Kumičić Elementary School in Slatina. He has obtained the aforementioned academic titles at the Croatian Studies at the University of Zagreb. He participated in the organization of VII. European Conference of Egyptologists (CECE7).

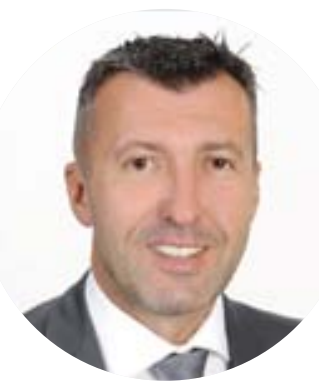

Marjan Ninčević

Marjan Ninčević, $\mathrm{PhD}$ is an assistant lecturer at the Department of Educational Sciences and Teacher Education at the Croatian Studies of University of Zagreb. In 2017 he was elected to the academic title of research scientist in the field of pedagogy. His research interests relate to school pedagogy and to the competence profile of teachers in the curriculum of modern schools. He represents a competence profile of contemporary teachers, the need to raise the quality of the process of education, the need for professional development of teachers and the development of intercultural competences.

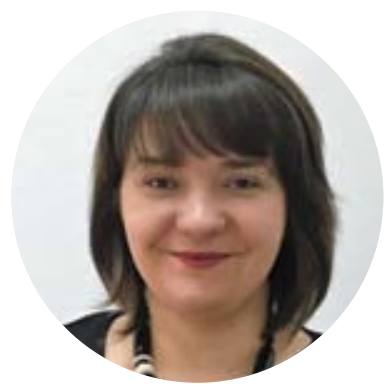

\section{Dunja Jurić} Vukelić

Dunja Jurić Vukelić works as a teaching assistant at the Department of Educational Sciences and Teacher Education, University of Zagreb Centre for Croatian Studies. She graduated Psychology in 2013 and is currently student of a post-graduate study Biomedicine and Health Science. Her professional interests concern quality of teaching, quality of teacher education and prevention of psychopathology in the education and health system. 